ORIGINAL ARTICLE

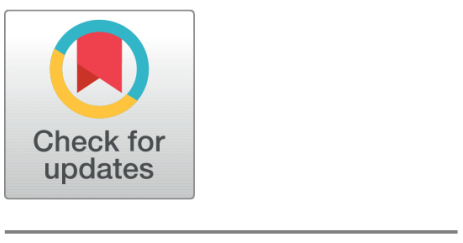

OPEN ACCESS

Received: 29-01-2020

Accepted: 07-02-2020

Published: 28-02-2020

Editor: Dr. D. R. Galfat

Citation: O' Reilly M, Flynn S, Lunn J (2020) Lateral clavicle fracture fixation in adolescents using an "Endobutton" technique. International Journal of Orthopaedics Traumatology \& Surgical Sciences 6(1): 30-34. https:// doi.org/10.47618/IJOTSS/v6i1.7

*Corresponding author.

marcoreilly@gmail.com

Funding: None

Competing Interests: None

Copyright: ( 2020 O' Reilly et al. This is an open access article distributed under the terms of the Creative Commons Attribution License, which permits unrestricted use, distribution, and reproduction in any medium, provided the original author and source are credited.

Published By Society of Orthopaedics, Surgical and Dental Sciences

\section{ISSN}

Print: 2455-0809

Electronic: 2454-4167

\title{
Lateral clavicle fracture fixation in adolescents using an "Endobutton" technique
}

\author{
Marc O' Reilly ${ }^{1}{ }^{*}$, Sean Flynn ${ }^{1}$, John Lunn ${ }^{1}$ \\ 1 Department of Trauma and Orthopaedic Surgery, "Midlands Regional Hospital Tullamore", \\ Arden Road, Tullamore, Co. Offaly, R35 NY51, Ireland
}

\section{Abstract}

Purpose: The purpose of this study was to assess if the use of the "endobutton" technique via an arthroscopically-assisted approach was associated with good patient reported outcome measures and low complication rates in select adolescent patients with displaced lateral third clavicle fractures. Methods: A retrospective review of displaced lateral third clavicle fractures sustained in adolescents treated operatively using the endobutton technique over a 2 year period was carried out at our institution. Four cases were identified, all sustained while involved in sporting activities and all were treated via an arthroscopically-assisted approach. Results: all 4 patients scored 0 on the Quick DASH assessment score. No hardware required removal and all patients returned to sport at the same level. Conclusions: Displaced lateral clavicle fractures in adolescents can pose a significant challenge in terms of management options. Use of the endobutton technique via an arthroscopicassisted approach can offer a safe and effective means of treatment with excellent patient reported outcomes and low complications rates. Level of Evidence: 4

Keywords: lateral clavicle; adolescent; arthroscopic-assisted

\section{Introduction}

Fractures of the clavicle account for almost $15 \%$ of all fractures seen in adolescents. ${ }^{(1,2)}$ The majority of fractures occur in the middle third or midshaft region with lateral third or distal fractures accounting for approximately one quarter. ${ }^{(1-6)}$ The most commonly affected patients are those aged between 13 and 20 years with the propensity for males being 2.5 times that for females. ${ }^{(7)}$ The incidence of clavicle fracture is estimated to be between 29 and 64 per 100,000 popu- lation with the main mechanism of injury being associated with sports. ${ }^{(7-9)}$

There is currently no level 1 evidence to guide the surgical treatment of clavicle fractures in the adolescent population and as such it has been mainly led by evidence deduced from adult studies. ${ }^{(7,10)}$ The clavicle reaches $80 \%$ of its growth by age 9 and 12 in girls and boys respectively and so this impacts on adolescent remodelling potential. ${ }^{(11)}$

Following our review of the literature there are no studies looking at the use of the endobutton technique for the 
treatment of adolescent displaced lateral clavicle fractures and the purpose of this case series is to present our experience of this modality in terms of operative approach and patient outcomes.

\section{Materials and methods}

A retrospective review of displaced lateral third clavicle fractures in adolescents treated operatively using the endobutton technique over a 2-year period (2014-2016) was carried out at our institution. Four cases were identified and written informed consent was obtained from all patients for clinical data usage. Patients' post-operative function was assessed using the Quick DASH score and all operations were carried out by the senior author. Operative technique was as follows:

The procedure was performed with the patient in the beach chair position. Antibiotic prophylaxis was used. A $4 \mathrm{~cm}$ vertical ('bra-strap') incision was made with its base centred on the coracoid process. The deltotrapezius fascia was incised perpendicular to the incision and released by sharp dissection from the clavicle to expose the fracture. An arthroscopic view of the underside of the coracoid in the glenohumeral joint was obtained through a posterior portal. An anterosuperior portal was created to allow placement of a wire using a jig (Arthrex, Naples). The clavicle was held reduced and the clavicle and coracoid were drilled with a cannulated drill. This allowed a lasso wire to shuttle the sutures and the button through the anterosuperior portal bringing the sutures out the clavicle drill hole. The fracture is then reduced after the button is toggled and the suture tensioned. We confirmed accurate reduction and toggling of the lower endobutton below the coracoid fluoroscopically before tying the suture ends over the proximal endobutton. The suture tails are then shuttled around the clavicle and through any bone attached to the CC ligament. These are also tied but behind the clavicle to reduce the large initial knot prominence. The arm was rested in a sling for four weeks after surgery with patients allowed assisted-active flexion to 90 degrees and removal of their sling in safe environments. After 4 weeks patients were advised to remove the sling and progress to active range of motion under physiotherapist supervision.

\section{Results}

Of the four cases identified there were 3 male and 1 female patient with an average age of 14.25 years. There were 2 left sided and 2 right sided fractures and they were classified as per the Rockwood and Dameron classification system as Type 5 fractures (See Figure 1 for example). The mechanism of injury was a mechanical fall while engaged in sport in all cases and average interval from time of injury to surgery was 10.25 days. All four cases were carried out via an arthroscopic-assisted approach with no operative complications. The average length of stay was 1 day with an average time to radiographic union of 6-12 weeks. Average interval from time of surgery to discharge from the senior authors service was 14.33 weeks. One of the patients did not attend any further follow up clinics after initial 2 week post-operative appointment and so this patient was not included in the average calculation for interval from time of surgery to discharge. All 4 patients scored 0 on the Quick DASH assessment score at 1 year post surgery. All patients were reviewed by the senior author in clinic and had no obvious prominence of the clavicular button or knot. All patients returned to sport and premorbid levels of activity. See Table 1 for results summary.

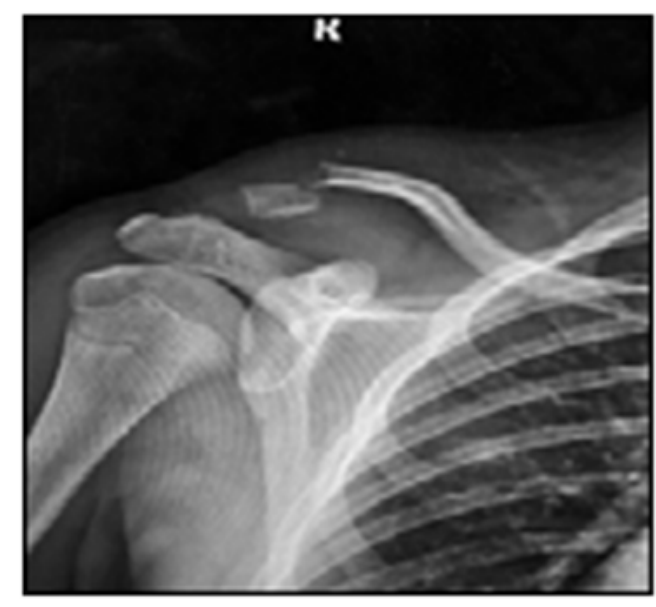

Fig 1. Pre-operative lateral clavicle fracture radiograph

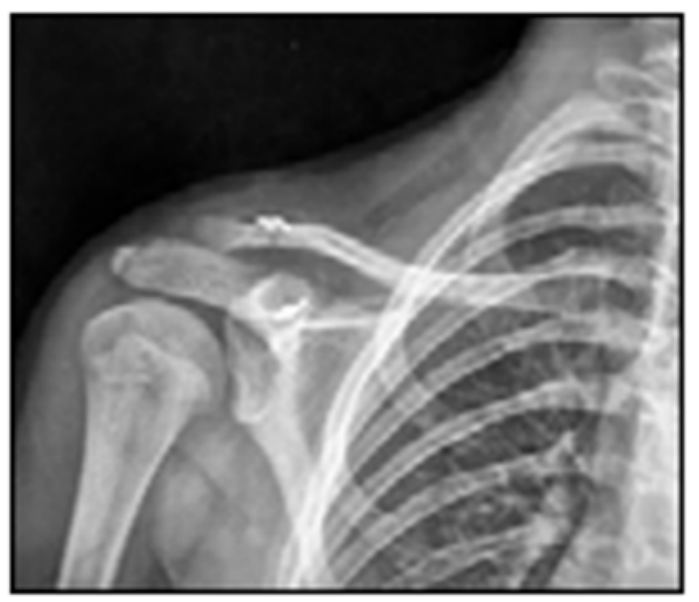

Fig 2. Post-operative radiograph

\section{Discussion}

Following our review of the literature we only found one publication discussing the use of the endobutton/tightrope procedure in adolescents but this is a narrative piece with no cases or patient reported outcomes quoted. ${ }^{(12)}$ To our knowledge 
Table 1. Summary of results

\begin{tabular}{|c|c|c|c|c|c|}
\hline Variable & Case 1 & Case 2 & Case 3 & Case 4 & Average \\
\hline Sex & M & $\mathrm{M}$ & M & $\mathrm{F}$ & - \\
\hline Age & 14 & 14 & 14 & 15 & 14.25 \\
\hline Side & Left & Left & Right & Right & - \\
\hline Mechanism of Injury & $\begin{array}{l}\text { Fall playing } \\
\text { Rugby }\end{array}$ & $\begin{array}{ll}\text { Fall from } \\
\text { bike }\end{array}$ & $\begin{array}{l}\text { Fall playing } \\
\text { soccer }\end{array}$ & $\begin{array}{ll}\begin{array}{l}\text { Fall } \\
\text { horse }\end{array} & \\
\end{array}$ & - \\
\hline Fracture type & Type 5 & Type 5 & Type 5 & Type 5 & - \\
\hline Interval from time of injury to surgery & 13 days & 8 days & 10 days & 10 days & 10.25 days \\
\hline Operative complications & Nil & Nil & Nil & Nil & - \\
\hline Length of stay & 1 day & 1 day & 1 day & 1 day & 1 day \\
\hline $\begin{array}{l}\text { Interval from time of surgery to outpatient } \\
\text { Discharge }\end{array}$ & 18 weeks & $\mathrm{n} / \mathrm{a}$ & 14 weeks & 11 weeks & 14.33 weeks \\
\hline Quick DASH score & 0 & 0 & 0 & 0 & 0 \\
\hline
\end{tabular}

this case-series is the first to describe the use of the endobutton technique for lateral clavicle fracture fixation in adolescents.

Whilst there is no level 1 evidence to definitively guide surgical management of adolescent clavicle fractures we felt that $100 \%$ or more displaced fractures with clinically significant subcutaneous fracture prominence were indicated for surgical fixation. The indications for lateral clavicle fracture fixation in adolescents are not well described but the limited literature designates Rockwood and Dameron Type 4 to 6 fractures as typically requiring surgical intervention. This classification system is paediatric and adolescent specific and has a total of six types which are based on the degree of periosteal sleeve disturbance and metaphyseal displacement. The presence of an intact coracoclavicular ligament is the main differentiation from the same injury in adults. ${ }^{(12,13)}$

Of the limited studies looking at operative intervention in adolescents the majority look at mid-shaft clavicle fractures. ${ }^{(2,4,14-17)}$ Some adolescent retrospective reviews have included lateral clavicle fractures in their studies but numbers are very small. Mehlman et al. looked at 24 cases in a retrospective review of operatively treated, completed displaced, clavicle shaft fractures where they found that surgical intervention was safe but this cohort only included one lateral fracture which was treated by screw fixation. ${ }^{(18)}$ A review of a 21 year period by Kubiak et al. of 15 patients treated operatively, showed satisfactory results but again had low numbers of lateral fractures, four in total, treated by k-wire fixation in 3 cases and a combination of osseous suture and screw fixation for another. ${ }^{(3)}$ Our review of the literature revealed only two studies looking specifically at adolescent lateral clavicle fracture fixation. One case series by Rashid et al showed good clinical and radiological outcomes in 5 patients treated with a tension band suture technique.13 Schilcher et al published a 7 patient case series using a transclavicular osseous suture technique which yielded excellent functional outcomes with all fractures healing uneventfully. ${ }^{(19)}$
The endobutton technique was initially developed to provide adequate reduction of ankle syndesmosis injuries but has been adopted by upper limb surgeons and is now a recognised means of treating acromioclavicular joint (ACJ) dislocations. ${ }^{(20-22)}$ As distal clavicle fractures are similar to ACJ dislocations in terms of the structures involved, it has now also been adopted for use in treating these fractures and provides a more flexible option which has been shown in biomechanical studies to be more superior to plating. ${ }^{(23-25)}$ Moreover it has been shown to be a safe and effective means of treating lateral clavicle fractures by both open and arthroscopic or arthroscopically-assisted approaches. ${ }^{(26-33)}$

Our case-series shows that the arthroscopic endobutton technique can provide a safe and effective means of treating displaced lateral clavicle fractures in select adolescent patients. It results in low complication rates, better cosmesis and excellent patient reported outcomes without the need for a secondary procedure of hardware removal as is required in other methods of fixation. ${ }^{(2,4,13,32,34)}$

We found an open superior incision was helpful to reduce the medial clavicle which displaces posterior as well as superiorly. In addition, early fracture healing in this adolescent population often interposed callus in the fracture site requiring removal before reduction was possible.

The authors are aware of the limitations of this study in terms of small patient numbers, lack of a control group and its retrospective nature. It does however contribute to the discussion on this challenging clinical scenario and reaffirms the need for further research in the form of prospective randomised studies.

\section{Conclusion}

Lateral clavicle fractures in adolescents can pose a significant challenge in terms of management options. Use of the tightrope procedure via an arthroscopic-assisted approach can offer a safe and effective means of treatment with excellent patient reported outcomes and low complications rates. 


\section{Compliance with Ethical Standards}

Funding: no funding was received for this study.

Conflict of interest: the authors have no conflict of interest to report.

Ethical approval: All procedures performed in studies involving human participants were in accordance with the ethical standards of the institutional and/or national research committee and with the 1964 Helsinki declaration and its later amendments or comparable ethical standards.

Informed consent: Informed consent was obtained from all individual participants included in the study.

\section{References}

1) van der Meijden OA, Gaskill TR, Millett PJ. Treatment of clavicle fractures: current concepts review. Journal of Shoulder and Elbow Surgery. 2012;21(3):423-429. Available from: https://dx.doi.org/10.1016/j.jse. 2011.08.053. doi:10.1016/j.jse.2011.08.053.

2) Have KLV, Perdue AM, Caird MS, Farley FA. Operative Versus Nonoperative Treatment of Midshaft Clavicle Fractures in Adolescents. Journal of Pediatric Orthopaedics. 2010;30(4):307-312. Available from: https://dx.doi.org/10.1097/bpo.0b013e3181db3227. doi:10.1097/bpo.0b013e3181db3227.

3) Kubiak R, Slongo T. Operative Treatment of Clavicle Fractures in Children: A Review of 21 Years. Journal of Pediatric Orthopaedics. 2002;22(6):736-739. Available from: https://dx.doi.org/10. 1097/01241398-200211000-00008. doi:10.1097/01241398-20021100000008.

4) Frye BM, Rye S, McDonough EB, Bal GK. Operative Treatment of Adolescent Clavicle Fractures With an Intramedullary Clavicle Pin. Journal of Pediatric Orthopaedics. 2012;32(4):334-339. Available from: https://dx.doi.org/10.1097/bpo.0b013e31825611da. doi:10.1097/bpo.0b013e31825611da.

5) Silva SR, Fox J, Speers M, Seeley M, Bovid K, Farley FA, et al. Reliability of Measurements of Clavicle Shaft Fracture Shortening in Adolescents. Journal of Pediatric Orthopaedics. 2013;33(3):e19e22. Available from: https://dx.doi.org/10.1097/bpo.0b013e318287f73f. doi:10.1097/bpo.0b013e318287f73f.

6) Caird MS. Clavicle Shaft Fractures. Ovid Technologies (Wolters Kluwer Health). 2012. Available from: https://dx.doi.org/10.1097/bpo. 0b013e31825870ad. doi:10.1097/bpo.0b013e31825870ad.

7) McIntosh AL. Surgical Treatment of Adolescent Clavicle Fractures. Journal of Pediatric Orthopaedics. 2016;36(1):S41-S43. Available from: https://dx.doi.org/10.1097/bpo.0000000000000757. doi:10.1097/bpo.0000000000000757.

8) Carry PM, Koonce R, Pan Z, Polousky JD. A survey of physi-cian opinion: adolescent midshaft clavicle fracture treatment prefer-ences among POSNA members. J Pediatr Orthop. 2011;31(1):44-53.

9) $\mathrm{Oh} \mathrm{JH}, \mathrm{Kim} \mathrm{SH}$, Lee JH, Shin SH, Gong HS. Treatment of dis-tal clavicle fracture: a systematic review of treatment modalities in 425 fractures. Arch Orthop Trau-ma Surg. 2011;131(4):525-558.

10) Pandya NK, Namdari S, Hosalkar HS. Displaced clavicle fractures in adolescents: facts, controversies, and current trends. J Am Acad Or-thop Surg. 2012;20(8):498-505.

11) McGraw MA, Mehlman CT, Lindsell CJ, Kirby CL. Postnatal Growth of the Clavicle: Birth to 18 Years of Age. Journal of Pediatric Orthopaedics. 2009;29(8):937-943. Available from: https://dx.doi.org/10.1097/bpo. 0b013e3181c11992. doi:10.1097/bpo.0b013e3181c11992.

12) Willimon SC, Ellis HB, Millett PJ. Distal Clavicle Fixation in the Skeletally Immature. Ovid Technologies (Wolters Kluwer Health). 2012. Available from: https://dx.doi.org/10.1097/bte.0b013e3182499ec8. doi:10.1097/bte.0b013e3182499ec8.
13) Rashid A, Christofi T, Thomas M. Surgical treatment of physeal injuries of the lateral aspect of the clavicle. The Bone \& Joint Journal. 2013;95B(5):664-667. Available from: https://dx.doi.org/10.1302/0301-620x. 95b5.31332. doi:10.1302/0301-620x.95b5.31332.

14) Namdari S, Ganley TJ, Baldwin K, Sampson NR, Hosalkar H, Nikci $\mathrm{V}$, et al. Fixation of Displaced Midshaft Clavicle Fractures in Skeletally Immature Patients. Journal of Pediatric Orthopaedics. 2011;31(5):507-511. Available from: https://dx.doi.org/10.1097/bpo. 0b013e318220ba48. doi:10.1097/bpo.0b013e318220ba48.

15) Eisenstein ED, Misenhimer JJ, Kotb A, Thabet AM. Abdelgawad Management of displaced midshaft clavicle fractures in ado-lescent patients using intramedul-lary flexible nails: A case series. JClin Orthop Trauma. 2018;9(1):97-102.

16) Schulz J, Moor M, Roocroft J, Bastrom TP, Pennock AT. Functional and Radiographic Outcomes of Nonoperative Treatment of Displaced Adolescent Clavicle Fractures. The Journal of Bone and Joint SurgeryAmerican Volume. 2013;95(13):1159-1165. Available from: https://dx. doi.org/10.2106/jbjs.1.01390. doi:10.2106/jbjs.1.01390.

17) Randsborg PH, Fuglesang HFS, Røtterud JH, Hammer OL, Sivertsen EA. Long-term Patient-reported Outcome After Fractures of the Clavicle in Patients Aged 10 to 18 Years. Journal of Pediatric Orthopaedics. 2014;34(4):393-399. Available from: https://dx.doi.org/10.1097/bpo. 0000000000000082. doi:10.1097/bpo.0000000000000082.

18) Mehlman CT, Yihua G, Bochang C, Zhigang W. Operative Treatment of Completely Displaced Clavicle Shaft Fractures in Children. Journal of Pediatric Orthopaedics. 2009;29(8):851-855. Available from: https://dx.doi.org/10.1097/bpo.0b013e3181c29c9c. doi:10.1097/bpo.0b013e3181c29c9c.

19) Schilcher J, Scheer J. Adolfsson Transclavicular Osseous Su-tures for the Treatment of Dis-placed Distal Clavicular Fractures in Children. $J$ Orthop Trauma. 2016;30(5):181-186.

20) Rios CG, Mazzocca AD. Acromioclavicular Joint Problems in Athletes and New Methods of Management. Clinics in Sports Medicine. 2008;27(4):763-788. Available from: https://dx.doi.org/10.1016/j.csm. 2008.06.006. doi:10.1016/j.csm.2008.06.006.

21) Horst K, Garving C, Thometzki T, Lichte P, Knobe M, Dienstknecht $\mathrm{T}$, et al. Comparative study on the treatment of Rockwood type III acute acromioclavicular dislocation: Clinical results from the TightRope technique vs. K-wire fixation. Orthopaedics \& Traumatology: Surgery \& Research. 2017;103(2):171-176. Available from: https://dx.doi.org/10. 1016/j.otsr.2016.11.009. doi:10.1016/j.otsr.2016.11.009.

22) Darabos N, Vlahovic I, Gusic N, Darabos A, Bakota B, Miklic D. Is AC TightRope fixation better than Bosworth screw fixation for minimally invasive operative treatment of Rockwood III AC joint injury? Injury. 2015;46:S113-S118. Available from: https://dx.doi.org/10.1016/j.injury. 2015.10.060. doi:10.1016/j.injury.2015.10.060.

23) Sambandam B, Gupta R, Kumar S, Maini L. Fracture of distal end clavicle: A review. Journal of Clinical Orthopaedics and Trauma. 2014;5(2):65-73. Available from: https://dx.doi.org/10.1016/j.jcot.2014. 05.007. doi:10.1016/j.jcot.2014.05.007.

24) Lädermann A, Gueorguiev B, Stimec B, Fasel J, Rothstock S, Hoffmeyer P. Acromioclavicular joint reconstruction: a comparative biomechanical study of three techniques. Journal of Shoulder and Elbow Surgery. 2013;22(2):171-178. Available from: https://dx.doi.org/10.1016/j.jse. 2012.01.020. doi:10.1016/j.jse.2012.01.020.

25) Rieser GR, Edwards K, Gould GC, Markert RJ, Goswami T, Rubino LJ. Distal-third clavicle fracture fixation: a biomechanical evaluation of fixation. Journal of Shoulder and Elbow Surgery. 2013;22(6):848-855. Available from: https://dx.doi.org/10.1016/j.jse. 2012.08.022. doi:10.1016/j.jse.2012.08.022.

26) Cho C, Bk, Kim D. Coracocla-vicular Stabilization Using a Su-ture Button Device for Neer Type IIB Lateral Clavicle Fractures. Arthroscopy: The Journal of Ar-throscopic \& Related Surgery. 2017;33(10):59-60.

27) Hohmann E, Hansen T, Tetsworth K. Treatment of Neer type II fractures of the lateral clavicle using distal radius locking plates combined with TightRope augmentation of the coraco-clavicular ligaments. Archives of Orthopaedic and Trauma Surgery. 2012;132(10):1415- 
1421. Available from: https://dx.doi.org/10.1007/s00402-012-1570-z. doi:10.1007/s00402-012-1570-z.

28) Joo SC, Sivapathasundaram N, Parthiban R, Ramanand A. A Technique of Distal Clavicle Fracture Fixation Using The Tightrope Procedure. Malaysian Orthopaedic Journal. 2011;5(3):20-23. Available from: https://dx.doi.org/10.5704/moj/1111.002. doi:10.5704/moj/1111.002.

29) Takase K, Kono R, Yamamoto K. Arthroscopic stabilization for Neer type 2 fracture of the distal clavicle fracture. Archives of Orthopaedic and Trauma Surgery. 2012;132(3):399-403. Available from: https://dx. doi.org/10.1007/s00402-011-1455-6. doi:10.1007/s00402-011-1455-6.

30) Loriaut P, Moreau PE, Dal-Laudiere B, Pelissier A, Vu HD, Massin P. Outcome of ar-throscopic treatment for displaced lateral clavicle fractures using a double button device. Knee Surg Sports Traumatol Arthrosc. 2015;23(5):1429-1462.

31) Flinkkila T, Heikkila A, Sirnio K, Pakarinen H. TightRope versus clavicular hook plate fixation for unstable distal clavicular frac-tures. Eur J
Orthop Surg Trauma-tol. 2015;25(3):465-474.

32) Robinson CM, Akhtar MA, Jenkins PJ, Sharpe T, Ray A, Olabi B. Open reduction and endobutton fixation of displaced fractures of the lateral end of the clavicle in younger patients. The Journal of Bone and Joint Surgery British volume. 2010;92-B(6):811-816. Available from: https://dx.doi.org/10.1302/0301-620x.92b6.23558. doi:10.1302/0301620x.92b6.23558.

33) Motta P, Bruno L, Maderni A, Tosco P, Mariotti U. Acute lateral dislocated clavicular fractures: arthroscopic stabilization with TightRope. Journal of Shoulder and Elbow Surgery. 2014;23(3):e47e52. Available from: https://dx.doi.org/10.1016/j.jse.2013.05.016. doi:10.1016/j.jse.2013.05.016.

34) Lee KW, Lee SK, Kim KJ, Kim YI, Kwon WC, Choy WS. Ar-throscopicassisted locking com-pression plate clavicular hook fixation for unstable fractures of the lateral end of the clavicle: a prospective study. Int Orthop. 2010;34(6):839-884. 